\title{
Clinical outcome in patients with acute coronary syndrome and outward remodeling is associated with a predominant inflammatory response
}

\author{
Alejandra Madrid-Miller ${ }^{1}$, Luis Chávez-Sánchez², Guillermo Careaga-Reyna ${ }^{3}$, Gabriela Borrayo-Sánchez ${ }^{4}$, \\ Karina Chávez-Rueda ${ }^{2}$, Silvestre Armando Montoya-Guerrero', Arturo Abundes Velazco ${ }^{5}$, \\ Mariano Ledesma-Velasco ${ }^{1}$, María Victoria Legorreta-Haquet ${ }^{2}$ and Francisco Blanco-Favela2 ${ }^{2 *}$
}

\begin{abstract}
Background: Pro-inflammatory molecules and low-density lipoproteins play essential roles in the atherosclerosis. The aim of our study was to establish an association among the cytokines secreted by peripheral blood mononuclear cells and the serum concentration in patients with unstable angina and coronary outward remodeling before and after percutaneous coronary intervention. The clinical and coronary responses were evaluated 6 months after the procedure.

Findings: Twenty-two patients with unstable angina were evaluated prior to after percutaneous coronary intervention and 6 months after procedure by coronary intravascular ultrasound. Eleven of the patients had recurrent angina, while 9 presented restenosis and an increase in the percentage of total plaque area. These 11 patients displayed higher levels of C-reactive protein than those without coronary events $(1.27 \mathrm{vs} .0 .43 \mathrm{mg} / \mathrm{dl}$, respectively; $P=0.029$ ) and a tendency to increase levels of interleukin (IL)- 8 and transforming growth factor- $\beta 1$, but lower levels of IL-10 (52.09 vs. $141.5 \mathrm{pg} / \mathrm{ml}$, respectively; $\mathrm{p}=0.035$ ). Activated peripheral blood mononuclear cells from patients with restenosis presented higher levels of proliferation, CD86 expression and higher IL-1, and increased IL-10 compared to those in patients without restenosis.

Conclusions: Patients with unstable angina and coronary outward remodeling who displayed a pro-inflammatory response experienced recurrent coronary events and an increased percentage of total plaque area. In contrast, better outcomes were observed in patients with anti-inflammatory responses. This response could be secondary to low-density lipoproteins.
\end{abstract}

Keywords: Acute coronary syndrome, Low-density lipoprotein, Inflammation

\section{Findings}

\section{Background}

The development and progression of coronary atherosclerotic lesions are characterized by lipid accumulation, cellular proliferation, and an inflammatory response, all of which causes changes in the vascular arterial wall [1]. These processes determine the plaque vulnerability, severity of lumen obstruction, and homodynamic and ischemic myocardial

\footnotetext{
* Correspondence: fblanco1@terra.com.mx

¿Unidad de Investigación Médica en Inmunología, Unidad Médica de Alta Especialidad, Hospital de Pediatría, Centro Médico Nacional Siglo XXI, Instituto Mexicano del Seguro Social, Avenida Cuauhtémoc 330, Col. Doctores, CP: 06720 México City, México

Full list of author information is available at the end of the article
}

repercussion [2,3]. Necropsy studies have demonstrated that lesion with positive or outward remodeling has higher lipid contents, as well as macrophage and other inflammatory cells counts, both markers of plaque vulnerability [4]. It seen that in patients with acute coronary syndrome, lipid accumulation in a culprit lesion is related with vascular expansion in atherogenesis. Additionally, remodeling of the arterial wall is an important mechanism in restenosis after percutaneous coronary interventions [3]. Angiographic follow-up studies have associated inflammatory activity with the frequency of restenosis, supported by the presence of inflammatory cells such as monocytes and $\mathrm{T}$ cells in the restenotic lesions $[5,6]$. 
However, until now, the nature of this inflammatory response has been controversial. Some of the possible triggers of the inflammatory response include Helicobacter pylori, Chlamydia pneumoniae and modified low-density lipoprotein (LDL) cholesterol [1,7]. Several studies have demonstrated that different forms of oxidized low-density lipoproteins (oxLDL) contribute to the development of atherosclerotic lesions through an inflammatory response $[8,9]$, supporting the idea that oxLDL may be a key antigen in atherosclerosis [7].

In addition, some studies have demonstrated that oxLDL activates different cell types and induces the secretion of pro-inflammatory interleukins (IL) such as IL-1 $\beta$ and IL-6 [10]. Others have shown that the T cells from patients with unstable angina (UA) can be activated with oxLDL; in contrast, $\mathrm{T}$ cells from stable patients exhibit a lower response to oxLDL [11]. Furthermore, native LDL (nLDL) increases the generation of vascular endothelial superoxide anions in situ, suggesting that it plays a role in the premature development of atherosclerosis [12].

However, specific mechanisms and temporal course of the complex interplay between mechanical dilatation, inflammatory response and corresponding changes in arterial anatomy and physiology are still poorly understood.

The aim of this study was to determine whether there is an association between the type of cytokines secreted from peripheral blood mononuclear cells (PBMCs) activated with nLDL in vitro and the serum cytokines concentrations, from patients with unstable angina and coronary outward remodeling before and after intravascular ultrasound-guided percutaneous coronary intervention (PCI), and the clinical and coronary responses were evaluated 6 months after the procedure.

\section{Methods}

\section{Patient population}

This study included 22 patients with unstable angina who were admitted to the Coronary Care Unit of the Hospital de Cardiología, Centro Médico Nacional "Siglo XXI". All of the patients were stable and had not experienced angina within the 48 hours before the procedure. Informed consent was obtained from all patients and healthy donors. The study was approved by the Human Ethics and Medical Research Committee of the Instituto Mexicano del Seguro Social (IMSS) and was conducted according to the Helsinki Declaration guidelines. The inclusion criteria included the following: a) patients younger than 75 years of age; b) angina duration less than 30 minutes, associated with an ST-segment depression of more than $1 \mathrm{~mm}$ or dynamic $\mathrm{T}$ wave changes at rest electrocardiogram during angina and no evidence of myocardial infarction detected with enzyme markers (MB creatine kinase and troponin I); c) patients eligible for percutaneous coronary intervention (PCI) with a bare metal stent implantation; d) it was necessary to confirm the presence of positive (or outward) artery remodeling at the culprit lesion with intravascular ultrasound images before coronary intervention. The exclusion criteria included the following: patients with recent bypass surgery or previous PCI; patients with left bundle branch block that invalidated ST-segment analysis, known malignancies, hematological and immunological disorders, any other inflammatory conditions or infections likely to be associated with the acute phase response, previous immunosuppressive or anti-inflammatory therapy, serum creatinine $\geq 1.5 \mathrm{mg} / \mathrm{dl}$ or known allergic reactions to iodine contrast medium. All patients received optimal anti-ischemic therapy (dual antiplatelet therapy with aspirin and clopidogrel, unfractionated heparin, intravenous nitroglycerine, beta blockers and statins), calcium channel blockers and ACE inhibitors, as required for each patient. All patients underwent laboratory tests, including those to measure total cholesterol, triglycerides, high density lipoprotein cholesterol, cholesterol LDL, white blood cell counts, creatinine and C-reactive protein.

Twelve healthy, normolipemic, 30- to 40-year-old volunteers without cardiovascular risk factors or clinically apparent atherosclerotic disease were also included as controls.

\section{Coronary angiography and intravascular ultrasound}

All patients underwent coronary angiography under the same conditions. The culprit lesion was defined by a significant stenosis $>50 \%$, abnormal thrombolysis in a myocardial infarction (TIMI) flow grade of 1 or 2 , or an intra-luminal defect strongly suggestive of a thrombus in the vessel lesion. The restenosis was defined as stenosis of $\geq 50 \%$ observed at the 6-month follow-up of the target lesion.

Intravascular ultrasound (IVUS) studies were performed using a commercially available CVI-INSIGHT system (Cardiovascular Imaging Systems, Inc.). In brief, this system consisted of a single-element $40 \mathrm{mHz}$ transducer mounted on the tip of a flexible beveled shaft within a 3.2 Fr short monorail polyethylene imaging sheath to allow the formation of planar images in real time. Prior to the IVUS studies, all patients received intracoronary nitroglycerine $(200 \mu \mathrm{g})$. The IVUS catheter was advanced $10 \mathrm{~mm}$ distal to the culprit lesion site. Studies were recorded for off-line analysis, as previously reported $[3,13]$. This recording was used to identify the corresponding image on the postintervention and control studies at the 6-month follow-up. The IVUS studies were performed in the same angiographic projection of the culprit lesion, and with data collected from the axial landmark (aorto-ostial junction to the target lesion), as reported previously [13].

\section{Quantitative coronary analysis}

Quantitative IVUS analysis included measurements of the external elastic membrane (EEM), cross-sectional 
area (CSA), lumen CSA, CSA of the plaque plus media (P\&M), percent plaque area and cross-sectional narrow (CSN). Measurements were taken at the site of the target lesion and in a proximal segment of the culprit artery, and the analysis was performed as previously reported [13]. The EEM CSA at the culprit lesion was compared to a proximal reference with the most normal-looking CSA (within $10 \mathrm{~mm}$ proximal). Outward remodeling was defined as lesion external elastic membrane (EEM) cross-sectional area (CSA) greater than the proximal reference.

\section{Percutaneous coronary intervention}

PCI with bare metal stent implantation in the target lesion was guided with IVUS. Procedure was considered successful if the final percentage of the residual stenosis was $<30 \%$ with a TIMI flow grade of 3 in the absence of recurrent myocardial ischemia, myocardial infarction, need of urgent coronary bypass surgery or death during the hospitalization period. A 6-month follow-up was performed in all patients unless the patient presented clinical indications for coronary angiography before this period of time. All of the angiograms and IVUS images were re-analyzed by two experienced, blinded cardiologists. An inter-observer variability with a kappa proportion of 0.83 was observed.

\section{LDL isolation}

Native LDL (nLDL) (density 1.019-1.063 g/ml) was isolated by sequential ultracentrifugation from the plasma of UA patients who were not candidates for PCI and from normolipemic donors. The plasma density was adjusted to $1.2 \mathrm{~g} / \mathrm{ml}$ by the addition of solid $\mathrm{KBr}$ (J.T. Baker, Phillipsburg, NJ, USA). The plasma solution was then distributed into polycarbonate centrifuge tubes, and a discontinuous density gradient was created by overlaying the plasma solution $(3 \mathrm{ml})$ with $3 \mathrm{ml}$ each of the following densities: $1.065 \mathrm{~g} / \mathrm{ml}, 1.020 \mathrm{~g} / \mathrm{ml}$, and $1.006 \mathrm{~g} / \mathrm{ml}$. The tubes were ultracentrifuged in a Beckman LX-90 ultracentrifuge equipped with an SW $40 \mathrm{Ti}$ rotor at $30,000 \mathrm{rpm}$ for 22 hours at $4^{\circ} \mathrm{C}$. After ultracentrifugation, the low-density lipoprotein was removed. The LDL fraction was dialyzed against phosphate-buffered saline (PBS) containing $0.01 \mathrm{M}$ phosphate (J.T. Baker, NJ, USA), $0.5 \mathrm{M}$ $\mathrm{NaCl}$ (Caledon Laboratories Ltd, Ont, Canada), and 0.5 mM EDTA (Sigma, St. Louis, MO, USA), pH 7.4, for 24 hours at $4^{\circ} \mathrm{C}$. The degree of oxidation of nLDL from patients and healthy donors was assessed by measuring thiobarbituric acid-reactive substances as previously described [14].

\section{Flow cytometry}

PBMCs were isolated from UA patients (before and 6 months after PCI) by density centrifugation using Lymphoprep (Axis-Shield, Liverpool, UK). The PBMCs were recovered from the interface, washed three times with PBS ( $\mathrm{pH}$ 7.4) and resuspended in RPMI (Invitrogen, Carlsbad, CA, USA) supplemented with $10 \%$ fetal bovine serum (FBS) (Invitrogen, Carlsbad, CA, USA). Subsequently, the PBMCs $\left(2 \times 10^{5} / \mathrm{ml}\right)$ were treated with $10 \mu \mathrm{g} / \mathrm{ml}$ of $\mathrm{nLDL}$ obtained from patients and healthy donors. As a negative control, PBMCs were cultured with RPMI (Invitrogen) supplemented with 10\% FBS (Invitrogen). For a positive activation control, PBMCs were plated at $2 \times 10^{5} / \mathrm{ml}$ in 96-well flat-bottomed tissue culture plates coated with anti-CD3 (BD Biosciences, CA). Regardless of treatment, all cells were incubated for $18,24,72$ and 168 hours at $37^{\circ} \mathrm{C}$. The PBMCs were then stained with antibodies specific for CD4, CD25, CD69, and CD86 or with isotype-control antibodies (all from BD Biosciences) for 20 minutes in the dark at $4^{\circ} \mathrm{C}$. The cells were then washed three times with PBS, fixed with $2 \%$ paraformaldehyde, and analyzed using a FACS Calibur flow cytometer (BD Biosciences).

\section{Proliferation assays}

PBMCs of UA patients were isolated prior to PCI and 6 months after PCI by density centrifugation using Lymphoprep (Axis-Shield). The PBMCs were recovered from the interface, washed three times with PBS ( $\mathrm{pH}$ 7.4) and resuspended in RPMI (Invitrogen) supplemented with $10 \%$ FBS (Invitrogen). The PBMCs $\left(2 \times 10^{5} / \mathrm{ml}\right)$ were then treated with $10 \mu \mathrm{g} / \mathrm{ml}$ of nLDL obtained from patients and healthy donors. As a negative control, PBMCs were cultured with RPMI (Invitrogen) containing 10\% FBS (Invitrogen) and for a positive control, the cells were cultured with anti-CD3 (BD Biosciences). After 3 days, the cells were pulsed with $1 \mathrm{uCi}\left[{ }^{3} \mathrm{H}\right]$ thymidine (GE Healthcare, Uppsala, Sweden) for an additional 3 days. The PBMCs were harvested into glass fiber filters, and the $\left[{ }^{3} \mathrm{H}\right]$ thymidine (GE Healthcare) incorporation was measured using a scintillation counter (Packard 1900TR counter).

\section{Cytokine assay}

PBMCs $\left(1 \times 10^{6} / \mathrm{ml}\right)$ from patients with UA (isolated prior to PCI and 6 months after procedure) were incubated with $10 \mu \mathrm{g} / \mathrm{ml} \mathrm{nLDL}$ obtained from patients and healthy donors. Concanavaline A (Sigma) was used as a positive control. As a negative control, the PBMCs were cultured with medium alone. The culture supernatants were collected after 18, 24 and 72 hours and 7 days of incubation at $37^{\circ} \mathrm{C}$. Additionally, sera were obtained from patients (prior to $\mathrm{PCI}$ and 6 months after PCI) for the measurement of cytokines. The levels of IL1 , IL-8, IL-10, and TGF- $\beta$ in the supernatants and sera were analyzed using commercial enzyme-linked immunosorbent assay (ELISA) kits (Biosource International, Camarillo, CA, USA) according to the manufacturer's instructions.

\section{Statistical analysis}

Because the results were not normally distributed, were expressed as medians and percentiles or ranges. Depending 
on the results obtained from the PCI, the patients were divided into two groups, those with recurrent angina or restenosis and those without recurrent events. Qualitative variables (dichotomy variables) were analyzed using the Chi-square test or Fisher's exact test. Nonparametric Wilcoxon tests were performed for quantitative paired variables (before and 6 months after PCI). MannWhitney $\mathrm{U}$ tests were used to compare independent groups (patients with and without recurrent angina or restenosis), and the association between inflammatory markers and clinical outcome was tested using Spearman's rho correlation coefficient. A one-tailed $p$-value of $\leq 0.05$ was considered significant with a $95 \% \mathrm{CI}$.

\section{Results}

\section{Patient characteristics}

The patients' median age was 61 years (range: 50 to 73 years old), and the sample included 14 men and 8 women. Of these, 7 had diabetes, 10 had systemic arterial hypertension, 14 were smokers, and 11 had dyslipidemia. All patients had experienced angina events previous to hospitalization, and 8 had prior myocardial infarctions. All patients were admitted with unstable angina considered intermediate or high risk.

\section{Intravascular ultrasound imaging \\ Correlation of angiographic results with clinical presentation and IVUS results}

The coronary angiography showed that 12 patients had single-vessel coronary disease, 8 had 2 -vessel disease, and 2 had 3 -vessel disease. The anterior descending artery was the most frequent culprit vessel (17 patients), while the culprit was the left circumflex in 3 cases and the right coronary in 2 patients. The most frequent target lesion type was B (5 patients with type B1 and 12 with type B2); in 5 cases we identified a type $C$ lesion. No significant differences in the type and severity of the coronary artery diseases between patients with or without recurrent ischemic events were observed. Qualitative analysis with IVUS showed that fibrolipidic-like atherosclerotic lesions were observed in the culprit vessel (11 cases) more often than lipidic (6 cases) or fibrotic (5 cases) lesions. In 9 patients, the imaging suggested calcium plaque (less than $90^{\circ}$ of the vessel circumference), with severe calcium deposition (more than $180^{\circ}$ ) in just 1 patient. Quantitative analysis was performed for all patients. The median EEM CSA was $16.3 \mathrm{~mm}^{2}$ (range: $10.5-25.7 \mathrm{~mm}^{2}$ ). The median vessel diameter was $4.5 \mathrm{~mm}$ (range: $3.5-5.7 \mathrm{~mm}$ ). The median lumen CSA was $2.2 \mathrm{~mm}$ (range: $1.8-2.8 \mathrm{~mm}$ ), and the median CSN was $72.2 \%$ (range: $54.3-83.8 \%$ ). There were no differences observed between patients with recurrent angina or restenosis and patients without recurrent ischemia at the time of follow-up. Only 1 patient presented coronary spasm as a complication of IVUS, and this was resolved with an intracoronary administration of verapamil and nitroglycerine. Angiographic success was obtained in all patients after the procedure, only 2 patients required 2 stents due to the length of the atherosclerotic plaque, but was not associated with recurrent ischemic events.

At the 6-month follow-up, 11 patients had recurrent angina. Of these, we identified restenosis of the target lesion by coronary angiography in 9 cases (left descending artery in 8 patients and circumflex in 1 patient). The cardiovascular risk factors and TIMI risk score were similarly distributed among patients with a new angina episode and patients without events. Systemic hypertension was the only risk factor that was significantly associated with recurrent ischemic events ( $\mathrm{p}=0.027, \mathrm{RR}=7.0,95 \% \mathrm{CI} 1.02$ - 47.81) (Table 1). No significant differences were found by quantitative IVUS analysis of the EEM CSA at 6 months. We found a significant increase $(\mathrm{p}=0.015)$ in the plaque percentage area in patients with restenosis (60.83\% [50.9-70.6\%]) compared to those without restenosis (48.25\% [42.8-60\%]). The patients with restenosis also had significantly higher $(\mathrm{p}=0.075)$ CSN gains $(8.48 \%$ [19.60 $\mathrm{a}-11.8 \%])$ than those without restenosis $(4.25 \%$ [23.9 - 3.2\%]) and in two patients was identified late stent malposition (Table 2). In addition, the patients with restenosis presented important neointimal hyperplasia (data not shown).

Determination of IL-8, CRP, IL-10, and TGF- $\beta$ levels in the sera We found a tendency of higher IL- 8 concentrations before intervention in patients with recurrent ischemic events when compared to the group of patients without recurrent

Table 1 Distribution of demographic characteristics and risk factors between patients

\begin{tabular}{lcc}
\hline & \multicolumn{2}{c}{ Recurrent agina or restenosis } \\
\cline { 2 - 3 } & Yes $(\mathbf{n}=\mathbf{1 1})$ & No $(\mathbf{n}=\mathbf{1 1})$ \\
\hline Age (years) & $63(50-70)$ & $57(55-73)$ \\
Male & 7 & 7 \\
Hypertension & $7^{*}$ & $1^{*}$ \\
Diabetes & 5 & 2 \\
Smoking & 8 & 5 \\
Hyperlipidemia & 6 & 5 \\
Previous angina & 7 & 2 \\
Previous Ml & 3 & $51(40-75)$ \\
Ejection fraction \% & $(49-75)$ & \\
Angiography & & 5 \\
1 vessel & 7 & 5 \\
2 vessels & 3 & 1 \\
3 vessels & 1 & 5 \\
\hline Sysmic hypertension & & 5 \\
\hline
\end{tabular}

Systemic hypertension was the only risk factor that was significantly associated with recurrent ischemic events $\left({ }^{*} p=0.027\right)$. 
Table 2 Quantitative IVUS image analysis in patients

\begin{tabular}{|c|c|c|}
\hline & \multicolumn{2}{|c|}{ Recurrent angina or restenosis } \\
\hline & Yes & No \\
\hline \multicolumn{3}{|l|}{ Before PTCA } \\
\hline EEM CSA $\left(\mathrm{mm}^{2}\right)$ & $16.4(10.5-25.7)$ & 16. (12.5-18.9) \\
\hline Lumen CSA $\left(\mathrm{mm}^{2}\right)$ & $4.23(3.10-6.40)$ & $4.95(3.4-6.4)$ \\
\hline Luminal diameter (mm) & $2.1(1.8-2.8)$ & $2.3(2.0-2.6)$ \\
\hline CSN (\%) & $76.65(57.4-83.8)$ & $64.6(54.3-77)$ \\
\hline Lesion length (mm) & $19.5(15.1-22.2)$ & $19.1(12.7-21.9)$ \\
\hline \multicolumn{3}{|l|}{ After PTCA } \\
\hline EEM CSA $\left(\mathrm{mm}^{2}\right)$ & $17.1(10.2-25.7)$ & $16.6(12.8-21.4)$ \\
\hline Lumen CSA $\left(\mathrm{mm}^{2}\right)$ & $8.9(5.8-16.5)$ & $8.95(6.3-11.5)$ \\
\hline Luminal diameter (mm) & $3.15(2.8-4.5)$ & $3.25(2.8-3.7)$ \\
\hline CSN (\%) & $45.4(36.10-62.3)$ & $48.13(43.7-62.7)$ \\
\hline Lumen area gain $\left(\mathrm{mm}^{2}\right)$ & $5.05(1-10)$ & $3.75(2.8)$ \\
\hline Lumen diameter gain (mm) & $1.10(0-2)$ & $0.91(0-2)$ \\
\hline \multicolumn{3}{|l|}{6 months } \\
\hline Outward remodeling & 5 pac. & 4 pac. \\
\hline $\operatorname{ATV}\left(\mathrm{mm}^{2}\right)$ & $16.80(10.5-24)$ & $14.9(10.0-23.5)$ \\
\hline LUMEN CSA $\left(\mathrm{mm}^{2}\right)$ & $5.95(3.9-9.1)$ & $8.6(6.0-12.0)$ \\
\hline Luminal diameter (mm) & $2.55(2.1-3.2)$ & $3.0(2.5-3.9)$ \\
\hline CSN (\%) & $60.83(50.9-70.6)^{* *}$ & $48.25(42.8-60)^{* *}$ \\
\hline Lumen CSA lost $\left(\mathrm{mm}^{2}\right)$ & $-1.40(-0.2$ a -3.2$)$ & $-0.55(-0.2 \mathrm{a}-6.6)$ \\
\hline CSN gain & $8.48(-11.8$ a 19.60$)$ & $4.25(-3.2$ a 23.9$)$ \\
\hline
\end{tabular}

The results from quantitative IVUS image analysis are similar between patients with and without recurrent ischemic events during follow-up. A significant increase in percent plaque area (CSN) was observed in patients with restenosis at the 6 -month follow-up $\left(^{* *} \mathrm{p}=0.015\right.$ by Mann-Whitney $\mathrm{U}$ test).

events, but this difference was not statistically significant $(24.19 \mathrm{pg} / \mathrm{ml}[9.15-77.49 \mathrm{pg} / \mathrm{ml}]$ in patients with recurrent events vs. $10.01 \mathrm{pg} / \mathrm{ml}[2.70-46.76 \mathrm{pg} / \mathrm{ml}]$ in those without recurrent events; correlation coefficient 0.408 , $\mathrm{p}=0.07)$. The same tendency was found at the 6-month follow-up $(11.9 \mathrm{pg} / \mathrm{ml}[4.85-42.28 \mathrm{pg} / \mathrm{ml}]$ in patients with favorable outcomes vs. $24.84 \mathrm{pg} / \mathrm{ml}[2.40-50.63 \mathrm{pg} / \mathrm{ml}]$ in patients with recurrent angina or restenosis, $\mathrm{p}=\mathrm{NS}$ ). Moreover, of the patients presenting elevated levels of $\mathrm{C}$ reactive protein, 9 of these had recurrent angina events or restenosis $(1.27 \mathrm{mg} / \mathrm{dl}[0.27-2.3 \mathrm{mg} / \mathrm{dl}]$ in patients with recurrent events vs. $0.43 \mathrm{mg} / \mathrm{dl}$, [0.01 $-0.8 \mathrm{mg} / \mathrm{dl}]$ in patients without events at 6 months, $p=0.029$ ). The IL-10 levels were higher in patients without recurrent events compared to those with recurrent events $(141.5 \mathrm{pg} / \mathrm{ml}[36.47-271.30 \mathrm{pg} / \mathrm{ml}]$ and $52.09 \mathrm{pg} / \mathrm{ml}[0.93-75.79 \mathrm{pg} / \mathrm{ml}]$, respectively; RR $0.25,95 \%$ IC [0.075 - 0.83], $\mathrm{p}=0.035)$. However, at the 6-month follow-up, both groups displayed similar values $(55.59 \mathrm{pg} / \mathrm{ml}[23.54-278.30 \mathrm{pg} / \mathrm{ml}]$ in the patients without recurrent ischemic events vs. $48.59 \mathrm{pg} / \mathrm{ml}[9.03-102.72 \mathrm{pg} / \mathrm{ml}]$ in those with recurrent ischemic events, $\mathrm{p}=\mathrm{NS}$ ). Moreover, we found an inverse correlation between the plasma levels of
IL-10 and the concentration of CRP (Spearman's rho correlation coefficient $0.477, \mathrm{p}=0.05$ ). In contrast, patients with recurrent ischemic events or restenosis of the target lesion had higher levels of TGF $\beta 1(1139.66 \mathrm{pg} / \mathrm{ml}$ $[632.43-1902.45 \mathrm{pg} / \mathrm{ml}])$ than patients with better outcomes $(854.71 \mathrm{pg} / \mathrm{ml}[161.44-1413.83 \mathrm{pg} / \mathrm{ml}])$, although this difference was not statistically significant. At the 6-month follow-up, the TGF $\beta 1$ levels were similar in both groups of patients $(1058.388 \mathrm{pg} / \mathrm{ml}$ [392.53- $2128.65 \mathrm{pg} / \mathrm{ml}]$ in those with recurrent ischemic events and $1006.49 \mathrm{pg} / \mathrm{ml}$ $[566.83-2380.30 \mathrm{pg} / \mathrm{ml}]$ in those without recurrent events, $\mathrm{p}=$ NS) (Figure 1).

\section{Surface expression of CD69, CD25, and CD86 on PBMCs}

Before PCI, the CD69 expression was 2.57\% [0.98 - 11.51\%] on the PBMCs from patients with recurrent angina or restenosis, compared to $1.27 \%$ [0.91 - 13.24\%] on those from patients without recurrent angina or restenosis $(\mathrm{p}=\mathrm{NS})$. The CD25 expression in these groups was $8.5 \%$ [0.10 - 16.72\%] and 15.06\% [6.62 - 25.07\%], respectively $(\mathrm{p}=\mathrm{NS})$. Similar results were found 6 months after coronary intervention in both groups. In contrast, CD86 expression remained elevated at the 6-month follow-up, principally in those patients with recurrent ischemic events $(12.17 \%$ [8.03 - 78.92\%] vs. $5.15 \%$ [3.43-62.56\%] in those without recurrent events prior to PCI and 38.38\% [7.65-68.14\%] in those with recurrent events vs. $10.47 \%$ [6.85-44.46\%] in those without recurrent events at 6 months following PCI.

\section{PBMC proliferation in response to $\mathrm{LDL}$}

We also investigated the effect of nLDL obtained from patients and healthy donors on the proliferation of PBMCs. As shown in Figure 2, the level of [3H] TdR uptake was relatively low $(1800 \mathrm{cmp}[145-8,148])$ in the negative control. In contrast, in the presence of LDL, the PBMCs of patients without recurrent angina or restenosis showed an increased proliferative response compared with the PBMCs cultured with medium alone. Moreover, the proliferative response to LDL was similar in all patients, although there was a tendency toward higher proliferation levels in the PMBCs from patients with recurrent angina or restenosis compared to those from patients without recurrent angina or restenosis (in response to nLDL obtained from patients: $6,717 \mathrm{cmp}$ [199-62,311] vs. 4,342 cmp [1,215-15,225], respectively; in response to nLDL obtained from healthy donors: 5,992 cmp [260-28,163] vs. $4,653 \mathrm{cmp}$ [1,097-27,245], respectively) (Figure 2).

\section{Activation of PBMCs in response to LDL}

We found that the expression of CD86 on PBMCs was elevated at different times in response to LDL in all patients, particularly in the PBMCs from patients with recurrent angina or restenosis at follow-up (24.94\% [0.89-91.63\%]), compared to the patients without recurrent events 


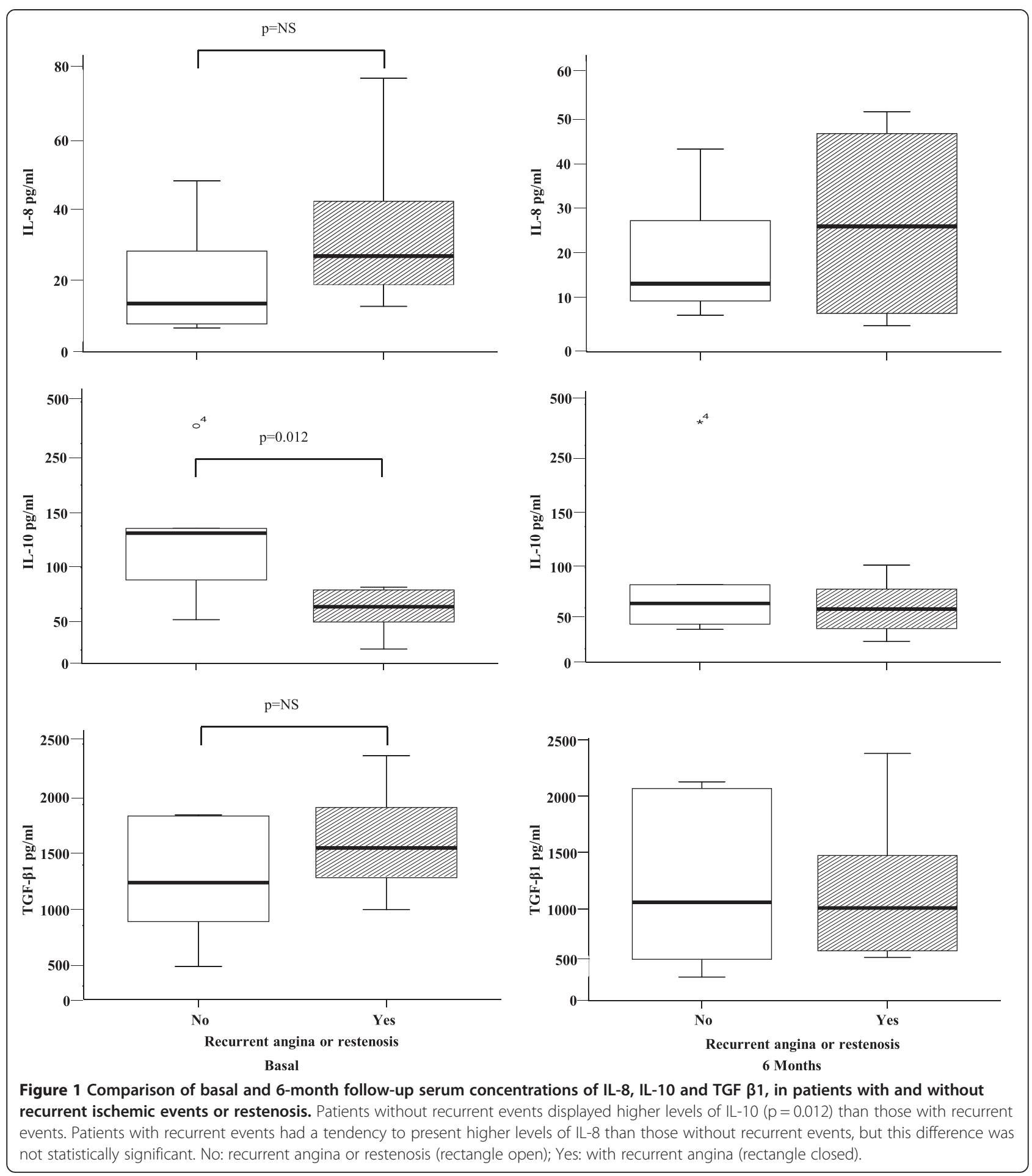

(18.40\% [5.71-55.10\%]). In contrast, there were no differences in the expression of CD69 or CD25 on the PBMCs of the patients following different lengths of LDL stimulation. There was actually a slight decrease in the expression of CD69 and CD25 following 48 hours of LDL stimulation, and the expression levels were similar at 7 days.
IL-1 and IL-10 production by LDL-stimulated PBMCs

We found that the in vitro nLDL stimulation of PBMCs from patients with or without restenosis resulted in increased IL-1 secretion, with a similar pattern observed at the 6-month follow-up. Conversely, increased IL-10 secretion was observed in activated PBMCs from the patients without restenosis at baseline and follow-up, 


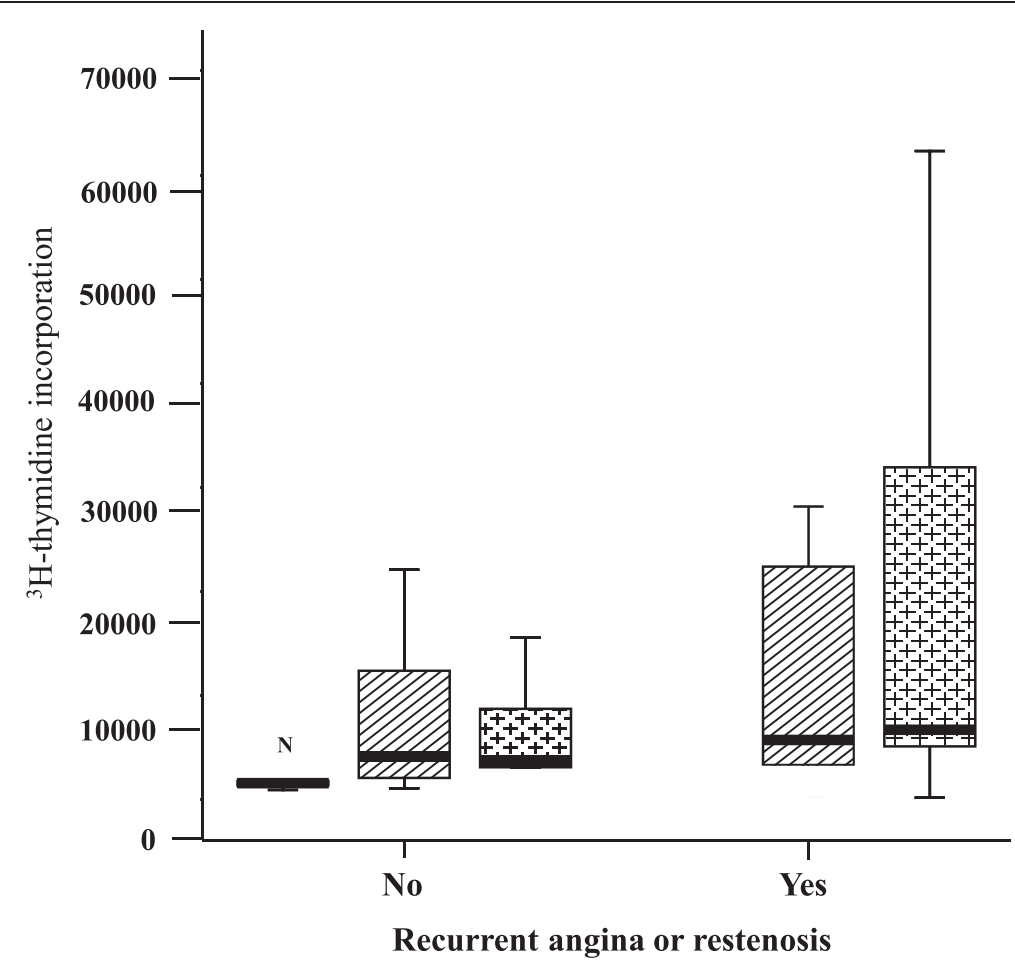

Figure 2 Proliferative responses to $\mathrm{LDL}$, expressed as $[3 \mathrm{H}]$ thymidine incorporation. Comparison of cellular responses from patients without recurrent angina (left) and those with ischemic events (right -YES-). At follow-up, the cells from patients with recurrent angina had a tendency of higher proliferative responses $(p=N S) .10 \mu \mathrm{g} / \mathrm{ml}$ of LDLH obtained from healthy donors (rectangle with diagonal lines); $10 \mu \mathrm{g} / \mathrm{ml}$ of LDLP obtained from patients (cross line), N (negative control).

while no differences in IL-10 secretion were observed in the cells from patients with restenosis or angina (Figure 3).

\section{Discussion}

Different publications have demonstrated that acute coronary syndrome can be characterized by unstable angina, non-ST-segment or ST-segment elevation myocardial infarction and chronic inflammation. It has also been suggested that an autoimmune mechanism could contribute to the atherosclerotic plaque progression and instability, where the oxidative modification of LDL played a pivotal role. Among others, these mechanisms include the increased expression of adhesion molecules on endothelial cells, monocyte activation, and pro-inflammatory cytokine secretion $[15,16]$. We found that patients with recurrent ischemic events or restenosis had a predominant proinflammatory response and an increased percentage of total plaque area in the culprit vessel 6 months after PCI. This ex vivo response was similar to the in vitro response of PBMCs activated with nLDL. Positive peri-stent vascular remodeling has been associated with stent thrombosis due to late acquired stent malposition and this has been reported more frequent with drug eluting stent. This situation was identified in only two patients as the cause of recurrent ischemic event, but all our patients underwent to bare metal stent implantation. Two mechanisms are thought to contribute to the development of late acquired stent malposition: decreased plaque volume behind the stent due to clot lysis or plaque regression, and positive remodeling of the vessel wall [17].

In our study, the inflammatory response was measured by elevated $C$ reactive protein levels, and this was associated with the recurrence of angina or restenosis at 6 months, similar to previous reports [1,2,12,14-20]. We found a tendency toward higher serum concentrations of IL-8 in those patients with restenosis compared to those without restenosis, in agreement with previous reports that predominantly pro-inflammatory responses are associated with poor prognoses [21]. However, we also observed that patients with higher levels of IL-10 had reduced frequencies of restenosis. IL-10 has been shown to have a modulatory effect on the immune response (most likely on the Th2 phenotype); this response indirectly inhibits the secretion of cytokines from Th1 cells, which inhibits the expression of cellular adhesion molecules and stimulates the production of granulocytemacrophage colony-stimulating factor, tissue factor and fibrinogen, as well as the proliferation of smooth muscle cells, cyclooxygenase 2 expression and cellular death [19-22]. By immunohistochemical analysis, Mallat et al. [23] demonstrated that low levels of IL-10 were associated with reduced nitric oxide production. Additionally, other reports have shown that low levels of IL-10 inhibit 

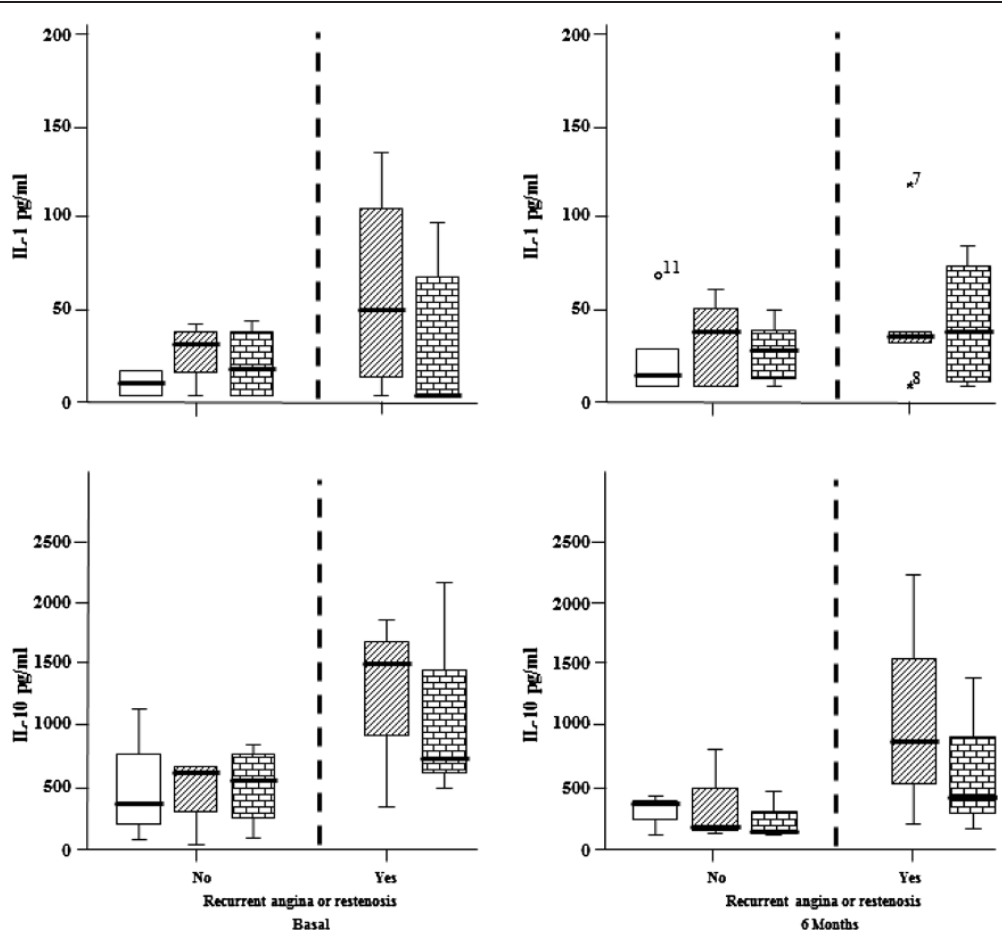

Figure 3 The interleukin concentrations were compared in the supernatants of cells from patients with recurrent angina or restenosis (left) and from those without recurrent ischemic events (right). Basal and 6-month follow-up results were also compared. Higher IL-10 concentrations were found in the samples from patients with recurrent events compared to those from patients without recurrent events (Median, 25th and 75th quartile). $10 \mu \mathrm{g} \mathrm{LDLH}=10 \mu \mathrm{g} / \mathrm{ml}$ of LDL obtained from healthy donors (rectangle with diagonal lines); $10 \mu \mathrm{g} L \mathrm{LP}=10 \mu \mathrm{g} / \mathrm{ml}$ of LDL from patients (rectangle with blocks); W/E: without stimulus (rectangle open).

the production of tumor necrosis factor alpha and nitric oxide while simultaneously protecting the ischemic and reperfused myocardium by reducing the recruitment of neutrophils [24-28]. The levels of this anti-inflammatory cytokine (IL-10) could be protective by regulating the effect of pro-inflammatory cytokines, reducing the possibility that an unstable atherosclerotic plaque will form and resulting in an improved prognosis [25]. Some other cytokines, such as IL-4, IL-1 receptor agonist and TGF $\beta 1$, have anti-inflammatory effects. However, until now, the role of TGF $\beta 1$ has been unclear, as clinical studies of this factor reported inconsistent results, with some associating elevated serum levels of activated TGF $\beta 1$ with increased severity of atherosclerotic coronary disease or recurrent acute ischemic events and others reporting the opposite. Other studies demonstrated that the administration of anti-TGF $\beta 1$ antibodies reduced the neointimal lesion area and inhibited the differentiation of Th17 cells, which play a critical role in the formation of atherosclerotic plaques [27-29]. In our study, patients with recurrent ischemic events or restenosis tended to display higher levels of activated TGF $\beta 1$, without an association with the number of vessels involved in the disease. It is likely that the secretion of activated TGF $\beta 1$ leads to an increase in the production of extracellular matrix and to plaque progression and disruption [25,29-33]. Moreover, we found elevated basal serum concentrations of activated TGF $\beta 1$ and lower IL-10 levels in patients with recurrent angina events or restenosis of the target lesion at the 6-month follow-up. This finding suggests that a $\mathrm{TH} 1$ phenotype response before coronary intervention was associated with restenosis at follow up, characterized by an increase in the percentage of total plaque area and neointimal hyperplasia without changes in arterial remodeling. There was no significant difference in the type of immune response between patients with or without recurrent ischemic events at 6 months after PCI. During the acute phase of unstable angina, the immune response could have prognostic value for percutaneous coronary interventions.

We decided to compare the effects of native LDL from patients and healthy donors, taking into account the fact that patients had higher levels of lipid peroxidation products and different LDL molecule characteristics, with smaller molecules and higher concentrations of cholesterol esters than healthy donors. Our results demonstrated higher levels of PBMC proliferation in response to stimulation with nLDL from patients with coronary artery disease (LDLnP) compared to stimulation with nLDL from healthy donors (LDLnH). Moreover, we analyzed CD86 expression 
ex vivo and found that the PBMC from patients with restenosis had higher CD86 expression levels than those from patients without restenosis. When we analyzed the biological effect of cellular activation with the two types of nLDL, our results showed that LDLnP tended to result in increased expression levels of CD86. It has been demonstrated that the stimulation of antigen presenting cells with oxLDL increases the expression of CD86 and that its interaction with CD28 induces the activation and proliferation of $\mathrm{T}$ lymphocytes, as well as the secretion of cytokines such as IFN- $\gamma[31,32]$. Furthermore, we found that the secretion of IL-1 $\beta$ was higher when PBMC were stimulated with LDLnP than with LDLnH. Previous reports have demonstrated that minimally modified LDL is capable of inducing the secretion of pro-inflammatory cytokines such as IL-1 $\beta$ and IL-6 [31a33]. However, we observed that LDLnH and LDLnP also induced IL10 secretion. Similar to our results, other studies have demonstrated that differentially modified forms of LDL induce RNA expression of IL10 and cytokine secretion, as a possible regulatory mechanism of cellular activation $[34,35]$.

\section{Conclusions}

The patients with acute coronary syndrome and outward remodeling at the culprit lesion artery were found to have a predominantly pro-inflammatory response, with poorer responses to interventional coronary procedures and increased frequencies of restenosis. Restenosis was associated with an increase in the percentage of total plaque area and a recurrence of angina events after 6 months. In contrast, a predominantly anti-inflammatory response was associated with protection and an improved outcome. It appears that LDL has pro-atherogenic properties and induces CD86 expression as well as the secretion of cytokines like IL-1 $\beta$, which participate in the atherosclerotic process.

\begin{abstract}
Abbreviations
oxLDL: Oxidized low-density lipoproteins; UA: Unstable angina; nLDL: Native low-density lipoprotein; PBMCs: Blood mononuclear cells; PCI: Intravascular ultrasound-guided percutaneous coronary intervention; IVUS: Intravascular ultrasound; EEM: External elastic membrane; CSA: Cross-sectional area; CRP: C-reactive protein; IL: Interleukin; TGF: Transforming growth factor.
\end{abstract}

\section{Competing interests}

The authors declare that they have no competing interests.

\section{Authors' contributions}

AMM, GCR and FBF conceived the idea and designed the experiments. AMM, LCS, KCR and MVLH performed the experiments of flow cytometer. LCS and KCR participated in the obtained of LDL, proliferation assays and cytokine assay. AMM, GBS and GCR participate in selection of patients and follow-up. AAV, MLV and SAMG participated in the Coronary angiography and intravascular ultrasound. AMM, AAV and MLV participated in the quantitative coronary analysis and percutaneous coronary intervention. AMM and GBS contributed in the performed the statistical analysis. AMM, LCS and FBF drafted the manuscript and interpretation of the data. All authors read and approved the final manuscript.

\section{Acknowledgments}

This research was supported by Fondo de Investigación en Salud del Instituto Mexicano del Seguro Social. Alejandra Madrid Miller, a student at the Programa de Master of Medical Science at the Universidad Nacional Autónoma de México (UNAM), was supported by a master fellowship from the Consejo Nacional de Ciencia y Tecnología and Instituto Mexicano del Seguro Social. We thank Alonzo Lee Autrey Caballero for support the development of this project.

\section{Author details}

'División de Investigación en Salud y Servicio de Hemodinamia de la Unidad Médica de Alta Especialidad, Hospital de Cardiología, Centro Médico Nacional Siglo XXI, Instituto Mexicano del Seguro Social, México, DF, México. ${ }^{2}$ Unidad de Investigación Médica en Inmunología, Unidad Médica de Alta Especialidad, Hospital de Pediatría, Centro Médico Nacional Siglo XXI, Instituto Mexicano del Seguro Social, Avenida Cuauhtémoc 330, Col. Doctores, CP: 06720 México City, México. ${ }^{3}$ Unidad Médica de Alta Especialidad, Hospital General del Centro Médico Nacional la Raza, Instituto Mexicano del Seguro Social, México, DF, México. ${ }^{4}$ Coordinación de Investigación en Salud, Centro Médico Nacional Siglo XXI, Instituto Mexicano del Seguro Social, México, DF, México. ${ }^{5}$ Servicio de Hemodinamia, Instituto Nacional de Cardiología, México, DF, México.

Received: 8 April 2014 Accepted: 18 September 2014 Published: 24 September 2014

\section{References}

1. Libby P: Inflammation in atherosclerosis. Nature 2002, 420:868-874

2. Tardif JC, Grégoire J, L'Allier PL, Ibrahim R, Lavoie MA, LeMay M, Cohen E, Levesque S, Keller PF, Heinonen T, Guertin MC: Effect of atherosclerotic regression on total luminal size of coronary arteries as determined by intravascular ultrasound. Am J Cardiol 2006, 98:23-27.

3. Tardif JC: The future of intravascular ultrasound in the detection and management of coronary artery disease. Can J Cardiol 2000, 16:12D-15D

4. Varnava AM, Mills PG, Davies MJ: Relationship between coronary artery remodeling and plaque vulnerability. Circulation 2002, 105:939-943.

5. Piek JJ, van der Wal AC, Meuwissen M, Koch KT, Chamuleau SA, Teeling P, van der Loos CM, Becker AE: Plaque inflammation in restenotic coronary lesions of patients with stable or unstable angina. J Am Coll Cardiol 2000, 35:963-967.

6. Cipollone F, Fazia M, lezzi A, Pini B, Costantini F, De Cesare D, Paloscia L, Materazzo G, D'Annunzio E, Bucciarelli T, Vecchiet J, Chiarelli F, Cuccurullo F, Mezzetti A: High preprocedural non-HDL cholesterol is associated with enhanced oxidative stress and monocyte activation after coronary angioplasty: possible implications in restenosis. Heart 2003, 89:773-779.

7. Ross R: The pathogenesis of atherosclerosis: a perspective for the 1990s. Nature 1993, 362:801-809.

8. Holvoet P, Mertens A, Verhamme P, Bogaerts K, Beyens G, Verhaeghe R, Collen D, Muls E, Van de Werf F: Circulating oxidized LDL is a useful marker for identifying patients with coronary artery disease. Arterioscler Thromb Vasc Biol 2001, 21:844-848.

9. Fernandes JL, Orford JL, Garcia C, Coelho OR, Gidlund M, Blotta MH: Differences in human antioxidized LDL autoantibodies in patients with stable and unstable angina. J Autoimmun 2004, 23:345-352.

10. Pasini AF, Anselmi M, Garbin U, Franchi E, Stranieri C, Nava MC, Boccioletti V, Vassanelli C, Cominacini L: Enhance levels of oxidized low-density lipoprotein prime monocytes to cytokine overproduction via upregulation of CD14 and Toll-like receptor 4 in unstable angina. Arterioscler Thromb Vasc Biol 2007, 27:1991-1997.

11. Caligiuri G, Paulsson G, Nicoletti A, Maseri A, Hansson GK: Evidence for antigen-driven T-cell response in unstable angina. Circulation 2000, 10:1114-1119

12. Stepp DW, Ou J, Ackerman AW, Welak S, Klick D, Pritchard KA Jr: Native LDL and minimally oxidized LDL differentially regulate superoxide anion in vascular endothelium in situ. Am J Physiol Heart Circ Physiol 2002, 283:H750-H759.

13. Mintz GS, Kent KM, Pichard AD, Satler LF, Popma JJ, Leon MB: Contribution of inadequate arterial remodeling to the development of focal coronary artery stenoses. An intravascular ultrasound study. Circulation 1997, 95:1791-1798. 
14. Pentikainen MO, Lindsted KA, Kovanen PT: Inhibition of the oxidative modification of LDL by nitecapone. Arterioscler Thromb Vasc Biol 1995, 15:740-747

15. Takei A, Huang Y, Lopes-Virella MF: Expression of adhesion molecules by human endothelial cells exposed to oxidized low density lipoprotein. Influences of degree of oxidation and location of oxidized LDL. Atherosclerosis 2001, 154:79-86.

16. Chávez-Sánchez L, Madrid-Miller A, Chávez-Rueda K, Legorreta-Haquet MV Tesoro-Cruz E, Blanco-Favela F: Activation of TLR2 and TLR4 by minimally modified low-density lipoprotein in human macrophages and monocytes triggers the inflammatory response. Hum Immunol 2010, 71:737-744

17. Kang KW1, Ko YG, Shin DH, Kim JS, Kim BK, Choi D, Hong MK, Kang WC, Ahn T, Jeon DW, Yang JY, Jang Y: Impact of positive peri-stent vascular remodeling after sirolimus-eluting and paclitaxel-eluting stent implantation on 5-year clinical outcomes. Intravascular ultrasound analysis from the poststent optimal stent expansion Trial Multicenter Randomized Trial. Circ J 2012, 76:1102-1108.

18. Ridker PM: Clinical application of C-reactive protein for cardiovascular disease detection and prevention. Circulation 2003, 107:363-369.

19. Ge C, Ren F, Lu S, Ji F, Chen X, Wu X: Clinical prognostic significance of plasma cystatin $C$ levels among patients with acute coronary syndrome. Clin Cardiol 2009, 32:644-648.

20. Lu HH, Sheng ZQ, Wang Y, Zhang L: Levels of soluble adhesion molecules in patients with various clinical presentations of coronary atherosclerosis. Chin Med J (Engl) 2010, 123:3123-3126.

21. Boekholdt SM, Peters RJ, Hack CE, Day NE, Luben R, Bingham SA, Wareham NJ, Reitsma PH, Khaw KT: IL-8 plasma concentrations and the risk of future coronary artery disease in apparently healthy men and women: the EPIC-Norfolk prospective population study. Arterioscler Thromb VasC Biol 2004, 24:1503-1508.

22. Wang XL, Liu SX, Wilcken DE: Circulating transforming growth factor beta 1 and coronary artery disease. Cardiovasc Res 1997, 34:404-410.

23. Mallat Z, Heymes C, Ohan J, Faggin E, Leseche G, Tedgui A: Expression of interleukin-10 in advanced human atherosclerotic plaques: relation to inducible nitric oxide synthase expression and cell death. Arterioscler Thromb Vasc Biol 1999, 19:611-616.

24. Selzman CH, Meldrum DR, Cain BS, Meng X, Shames BD, Ao L, Harken $\mathrm{AH}$ : Interleukin-10 inhibits postinjury tumor necrosis factor-mediated human vascular smooth muscle proliferation. J Surg Res 1998, 80:352-356.

25. Anguera I, Miranda-Guardiola F, Bosch X, Filella X, Sitges M, Marin $J L$, Betriu A, Sanz G: Elevation of serum levels of the anti-inflammatory cytokine interleukin-10 and decreased risk of coronary events in patients with unstable angina. Am Heart J 2002, 144:811-817.

26. Yang Z, Zingarelli B, Szabo C: Crucial role of endogenous interleukin-10 production in myocardial ischemia/reperfusion injury. Circulation 2000 , 101:1019-1026.

27. Suwanabol PA, Kent KC, Liu B: TGF- $\beta$ and restenosis revisited: A Smad link J Surg Res 2011, 167:287-297.

28. Morishima N, Mizoguchi I, Takeda K, Mizuguchi J, Yoshimoto T: TGF-beta is necessary for induction of IL-23R and Th17 differentiation by IL- 6 and IL-23. Biochem Biophys Res Commun 2009, 386:105-110.

29. Gao Q, Jiang Y, Ma T, Zhu F, Gao F, Zhang P, Guo C, Wang Q, Wang X, Ma C, Zhang Y, Chen W, Zhang L: A critical function of Th17 proinflammatory cells in the development of atherosclerotic plaque in mice. $J$ Immunol 2010, 185:5820-5827.

30. Smith DA, Irving SD, Sheldon J, Cole D, Kaski JC: Serum levels of the anti-inflammatory cytokine interleukin-10 are decreased in patients with unstable angina. Circulation 2001, 104:746-749.

31. Zaguri R, Verbovetski I, Atallah M, Trahtemberg U, Krispin A, Nahari E, Leitersdorf E, Mevorach D: 'Danger' effect of low-density lipoprotein (LDL) and oxidized LDL on human immature dendritic cells. Clin Exp Immunol 2007, 149:543-552.

32. Acuto O, Michel F: CD28-mediated co-stimulation: a quantitative support for TCR signalling. Nat Rev Immunol 2003, 3:939-951.

33. Chávez-Sánchez L, Chávez-Rueda K, Legorreta-Haquet MV, Zenteno E, Ledesma-Soto Y, Montoya-Díaz E, Tesoro-Cruz E, Madrid-Miller A, Blanco-Favela F: The activation of CD14, TLR4, and TLR2 by mmLDL induces IL-1 $\beta$, IL-6, and IL-10 secretion in human monocytes and macrophages. Lipids Health Dis 2010, 9:117.
34. Fei GZ, Huang YH, Swedendorg J, Frostegård J: Oxidised LDL modulates immune-activation by an IL-12 dependent mechanism. Atherosclerosis 2003, 169:77-85.

35. Bae YS, Lee JH, Choi SH, Kim S, Almazan F, Witztum JL, Miller Yl: Macrophages generate reactive oxygen species in response to minimally oxidized Low-density lipoprotein: toll-like receptor 4- and spleen tyrosine kinase-dependent activation of NADPH oxidase 2. Circ Res 2009, 104:210-218.

doi:10.1186/1756-0500-7-669

Cite this article as: Madrid-Miller et al.: Clinical outcome in patients with acute coronary syndrome and outward remodeling is associated with a predominant inflammatory response. BMC Research Notes 2014 7:669.

\section{Submit your next manuscript to BioMed Central and take full advantage of:}

- Convenient online submission

- Thorough peer review

- No space constraints or color figure charges

- Immediate publication on acceptance

- Inclusion in PubMed, CAS, Scopus and Google Scholar

- Research which is freely available for redistribution 